\title{
Investigation of interactions between two monoclonal antibodies and SARS virus with a Label-free Protein Array
}

\author{
C. Qi ${ }^{\mathrm{a}}{ }^{\mathrm{b}}, \mathrm{Y}-\mathrm{Y}$ Chen ${ }^{\mathrm{a}, \mathrm{b}}, \mathrm{Z}-\mathrm{H} . \mathrm{Wang}^{\mathrm{a}}$, G. Jin ${ }^{\mathrm{a} *}$ \\ ${ }^{a}$ Institute of Mechanics, Chinese Academy of Sciences, \#15, Bei-si-huan West Rd., Beijing 100080, P.R.China \\ ${ }^{\mathrm{b}}$ Graduate School of Chinese Academy of Sciences, \#19, Yu-quan Rd, Shi-jing-shan District, Beijing 100039, P.R. China \\ *Tel./Fax: +86-10-62631816, E-mail: gajin@imech.ac.cn
}

\begin{abstract}
The investigation of interactions between two kinds of monoclonal antibodies and SARS virus with a labelfree protein array technique were presented in this paper. The performance consists of three parts: a surface modification for ligand immobilization/surface, a protein array fabrication with an integrated microfluidic system for patterning, packaging and liquid handling, and a protein array reader of imaging ellipsometer. This revealed the technique could be used as an immunoassay for qualitative and quantitative detection as well as kinetic analysis of biomolecule interaction.
\end{abstract}

Keywords-Protein array, SARS, antibody

\section{INTRODUCTION}

Severe acute respiratory syndrome (SARS) is a viral respiratory illness caused by a coronavirus, called SARSassociated coronavirus (SARS-CoV) [1-4]. SARS was first reported in Asia in February 2003. By July 2003, the international spread of SARS-CoV resulted in 8098 SARS cases in 26 countries, with 774 deaths. The epidemic caused significant social and economic disruption in areas with sustained local transmission of SARS and on the travel industry internationally in addition to the impact on health services directly. Since July 2003, there have been four known reoccurrences of the SARS virus, which indicates that the resurgence of SARS leading to an outbreak remains a distinct distinctly possible. Thus it is imperative that world health authorities and the global population in general remain vigilant against a resurgence of the virus. The development of a human neutralizing antibody to the SARS virus is a relatively rapid approach to obtain an agent that can limit the disease in infected and exposed individuals.

The biosensor concept based on imaging ellipsometry for visualization of biomolecular interactions was reported in $1995[5,6]$. The label-free protein array presented in this paper was developed for the biosensor.

This label-free protein array technique consists of three parts: a surface modification for oriented ligand immobilization; an integrated microfluidic system for protein array fabrication, packaging and liquid handling, and an imaging ellipsometer used as a protein array reader.

The applications of this technique mainly focused on biomedical fields. Thus far, the technique has been used successfully in a number of scenarios, for example in, 1) biomolecule interaction [7]; 2) hormone detection [8]; 3) cell factor and its receptor interaction [9]; 4) cancer marker test [10]; 5) mono-clone medicine evaluation [11]; 6) clinic diagnosis for hepatitis $\mathrm{B}$ [12]; 7) quantitative protein competitive adsorption [13-15]; 8) kinetic detection for multi-protein interaction process [16,17], etc. For this study, this technique was used to study the interaction between a coronavirus which can result in severe acute respiratory syndrome (SARS) and two kinds of its monoclonal antibodies.

\section{Methodology}

\section{A. Principle}

A ligand and its receptor, for example an antibody and its corresponding antigen, are able to assemble into complexes due to their affinity. The optical biosensor works on the basis that each reactant as a ligand is immobilized on a surface. Following this, a monolayer is formed as a bioprobe with its bioactivity. The other reactant as the analyte (or receptor) exists in a solution, and bioprobe is exposed to the solution containing analyte. When the analyte in the solution interacts with its corresponding ligand on the bioprobe, it then assembles into complex upon their affinity. The molecule surface concentration on the surface where the interaction takes place becomes higher than before exposure to the analyte solution. A significant increase in the layer's thickness (mass surface concentration) indicates that the solution contained receptor against the ligand on the surface. With a visualization of imaging ellipsometry, which has a high spatial resolution in the order of $0.1 \mathrm{~nm}$ in vertical and micron in lateral, the increase can be determined, and in this way, the existence of the analyte in the solution can be verified. Many bio-probes arrayed in matrix are used for multi-detection [17-19].

\section{B. Proteins and Chemicals}

Silicon wafers were purchased from General Research Institute for Nonferrous Metals. Tween 20 was purchased from Sigma-Aldrich. 3-aminopropyltriethoxy-silane (99\%, $\mathrm{v} / \mathrm{v})$ was purchased from ACROS. Glutaraldehyde $(50 \%$ aqueous solution photographic GRA) was purchased from SIGMA. All chemicals used were of analytical grade. Antibody b1 $(137 \mu \mathrm{g} / \mathrm{ml}$, MW 29KD) and antibody h12 $(78 \mu \mathrm{g} / \mathrm{ml}, \mathrm{MW} 29 \mathrm{KD})$ and SARS-CoV were provided from the Institute of Biophysics, Chinese Academy of Sciences. The Antibodies were the positive $\mathrm{ScFv}$ screened from the phage-display library of serum extracted from SARS- 
recovered donors. Bovine serum albumin (BSA) was purchased from SIGMA. Phosphate-buffered saline (PBS; $10 \mathrm{mM}$ phosphate, $0.1 \mathrm{M} \mathrm{NaCl} \mathrm{pH7.2)} \mathrm{was} \mathrm{prepared} \mathrm{in}$ deionized water. Pure water (Resistivity $18.3 \mathrm{M} \Omega \mathrm{cm}$ ) was produced by ion exchange demineralization, after which it passed through a Milli-Q plus system from Millipore (Millipore, Bedford, MA). Real-time spectroscopic ellipsometry experiments were performed with a variable angle spectroscopic ellipsometer of J. A. Woollam Co.

\section{Protein solution preparation}

The antibody h12 and antibody b1 were diluted once using PBS solution with $1 \%$ tween 20 to the concentration $68.5 \mu \mathrm{g} / \mathrm{ml}$ and $39 \mu \mathrm{g} / \mathrm{ml}$ respectively to enable qualitative detection. The antibody b1 and antibody $\mathrm{h} 12$ were diluted to $82.2 \mu \mathrm{g} / \mathrm{ml}$ and $34 \mu \mathrm{g} / \mathrm{ml}$ in PBS with $1 \%$ tween 20 respectively for real time analysis.

\section{Cleaning of silicon wafers}

The silicon wafers were cut into rectangles $20 \times 5 \mathrm{~mm}$ and cleaned in deionized water. The wafer surface was washed in solution $\left(30 \% \mathrm{H}_{2} \mathrm{O}_{2}: 98 \% \mathrm{H}_{2} \mathrm{SO}_{4}=1: 3 \mathrm{v} / \mathrm{v}\right)$ for $30 \mathrm{~min}$, thus making the surface hydrophilic. After thoroughly rinsed with water and pure ethanol, the slides were stored in pure ethanol before use.

\section{E. Silanization of cleaned silicon wafers}

The cleaned wafers were incubated in a mixture of 3Aminopropyltriethoxy-silane(APTES 99\%, v/v) and absolute ethanol (3-Aminopropyltriethoxy-silane: absolute ethanol $=1: 10 \mathrm{v} / \mathrm{v}$ ) for $2 \mathrm{~h}$ at room temperature. Following this, they were again rinsed in absolute ethanol three times and de-ionized water three times. Before immobilization of proteins, the silicon wafers silanized with APTES were reacted with a $2.5 \%$ solution of glutaraldehyde in PBS for $1.5 \mathrm{~h}$, followed by rinsing with PBS buffer. This procedure introduced aldehyde groups on the silicon surface that can react with amino groups of the proteins to immobilize protein molecules covalently on surface.

\section{F. Integrated micro-fluidic system}

An integrated microfluidic system was fabricated using multilayer soft lithography, which can not only be used to fabricate protein array but also serve as packaging system and micro-reactor for protein array. Protein molecules can be patterned homogeneously on substrate to form protein array by the microfluidic system, and the patterning step is local, that is, exposure of protein molecules to the substrate occurs only on targeted areas. Simultaneous immobilizations of proteins on these targeted areas are possible without the introduction of cross-interferences, even where different coupling chemistries are needed. After fabrication, the protein array can be stored in the packaging system which is full of buffer so that proteins are not exposed to denaturing conditions. The spots on protein array can be divided into different groups and connected respectively in series by the microfluidic system to react with different samples simultaneously under dynamic condition, This is in contrast to conditions that occur when using a conventional protein array, which only allows for reactions with a single sample under static conditions.

\section{G. Imaging ellipsometer}

A fully automatic imaging ellipsometer developed in our laboratory was used as a protein array reader. Imaging ellipsometry was an enhancement of standard single-beam ellipsometry, which combined the power of ellipsometry with microscopy and worked in the off-null mode [17]. The imaging ellipsometry used in this study was an automated one and ellipsometric conditions could be controlled by an auto-adjusting a polarizer and an analyzer; the angle of incidence was variable from $45 \sim 90^{\circ}$ with a resolution of $0.05^{\circ}$; the magnification of image to object is modulated according to the dimension of the field of view, so that the lateral resolution of $3 \mu \mathrm{m}$ could be reached; auto-focusing was realized with the standard of the Laplacian algorithm. All the adjustments were carried out automatically with micro-stepping motors controlled by a computer with homemade software. With the same software, the digital images in grayscale format ( 8 bits, $0 \sim 255$ grayscale) could be also automatically captured and processed. The light source was a Xenon lamp, and a specific collimating system was used to provide an expanded parallel probe beam with a diameter of about $25 \mathrm{~mm}$. The beam passed through a polarizer and a compensator (a quarter wave plate) and finally onto the sample at an incident angle of $75^{\circ}$. An optical filter at 633 $\mathrm{nm}$ wavelength was placed in the incident optical passage to select wavelength in order to increase the ellipsometric contrast of image. The reflection beam passed through the analyzer and an imaging lens with a spatial filter located at its focus plane, and then the ellipsometric image was focused onto the sensing area of the CCD camera. For a sample with lateral distribution of layer thickness (or surface concentration), null ellipsometry could not be carried out over the entire surface simultaneously due to the fact that different areas would yield different polarization changes. In order to overcome the problem, the optical components in the system were adjusted to fulfill the null conditions on a silicon wafer without adsorbed layers and the off-null ellipsometric principle was used to measure the adsorption layer thickness (or surface concentration). Under this condition, the detected intensity "I" was related to the thickness (d) of the layer according to $\mathrm{I}=\mathrm{kd}^{2}$. As for the same protein and the same ellipsometric conditions, $\mathrm{k}$ is a constant and can be determined by the protein layer with known intensity in grayscale and its absolute thickness. In this paper, the absolute thickness of protein layer was calibrated by conventional ellipsometer. The relationship between surface concentration and protein layer thickness 
was: surface concentration $\left(\mu \mathrm{g} / \mathrm{cm}^{2}\right) \approx \mathrm{K} \times \mathrm{d}(\mathrm{nm})$, where $\mathrm{K} \approx 0.12$ [16].

\section{INTERACTION BETWEEN ANTIBODY AND SARS VIRUS}

\section{A. Microarray test}

The interactions between these monoclonal antibodies and SARS virus were investigated using single protein array. The SARS virus was first immobilized on six spots of protein array using the microfluidic system. After being blocked with BSA, the two monoclonal antibodies' solutions were pumped into the microfluidic system in order to ellicit a reaction with SARS virus. The imaging ellipsometer was used for the protein array reading, and the ellipsometric contrast image of the protein array was shown in Fig. 1A and the corresponding biomolecule surface concentration map shown in Fig. 1B. There were six spots with SARS virus on the protein array. Of the six, two reacted with monoclonal antibody b1, another two reacted with monoclonal antibody h12, two were left as reference. Significant increase of protein surface concentration occurred on the spots where reacted with monoclonal antibodies, which indicated that these two monoclonal antibodies could bind with SARS virus.

\section{B. Real time analysis of interaction between antibody and SARS virus}

The real time experiments were performed according to the method described in literature [7]. A reaction cell was designed for real-time monitoring the interaction between antibody in solution and SARS virus on the protein array. The volume of the cell was $0.5 \mathrm{ml}$ and it had two optical windows for the probe light beam of ellipsometry in and out. The normal of the two windows were parallel to the incident direction and the reflection direction of the probe light. The windows with optical quality were transparent for the probe light.

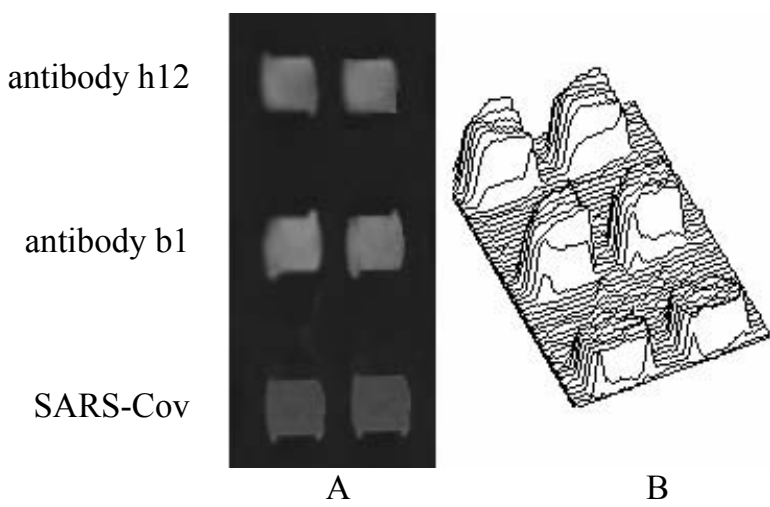

Fig.1. Detection of interaction between two monoclonal antibodies and SARS virus with single protein array. The result was shown in the ellipsometric contrast image (A) and the corresponding biomolecule surface concentration map (B).



Fig.2. The interaction between monoclonal antibody b1 and SARS virus was illustrated by a plot of the surface concentration of b1 versus time.

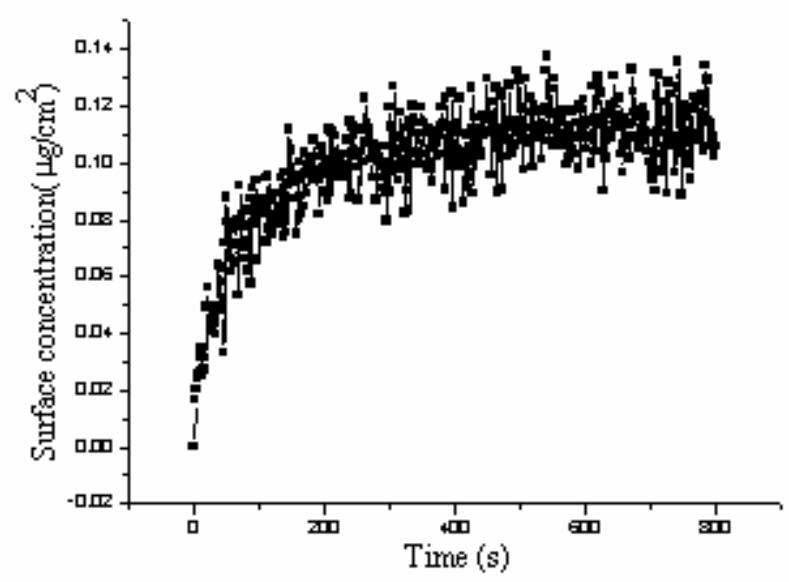

Fig.3. The interaction between monoclonal antibody h12 and SARS virus was illustrated by a plot of the surface concentration of b1 versus time.

The antibody solution could be poured into the cell and pumped out by a pump. The cell was located on the sample supporter crossing the probe beam. The protein array with SARS virus was inserted into the cell and illuminated by the main beam of the probe light. When the antibody solution was poured into the cell, the antibody in the solution would bind to SARS virus on the protein array, thus the surface concentrations of biomolecules on spot increased. The growth of the surface concentrations was recorded, and the binding curves in real-time were obtained in real-time by plotting the surface concentrations verse the reaction time. The results for monoclonal antibody b1 and h12 were shown in Fig. 2 and Fig. 3, respectively.

The association/dissociation rate and affinity constants for these two monoclonal antibodies to SARS virus were obtained by the method described in literature [19]. Theassociation rate constant $\mathrm{k}_{\mathrm{a}}$ for antibody $\mathrm{b} 1$ to SARS virus was7.5 $\times 10^{3} \mathrm{M}^{-1} \mathrm{~S}^{-1}, \mathrm{k}_{\mathrm{d}} 6.6 \times 10^{-4} \mathrm{~S}^{-1}$, and affinity constant $\mathrm{K}_{\mathrm{A}} 1.36 \times 10^{7} \mathrm{M}^{-1}$. For antibody $\mathrm{h} 12, \mathrm{k}_{\mathrm{a}}$ was $5.22 \times 10^{3} \mathrm{M}^{-1} \mathrm{~S}^{-1}, \mathrm{k}_{\mathrm{d}} 5.5 \times 10^{-4} \mathrm{~S}^{-1}$, and affinity constant $\mathrm{K}_{\mathrm{A}} 9.5 \times 10^{6} \mathrm{M}^{-1}$. 


\section{CONCLUSION}

The label-free protein array technique was used for the investigation of interactions between two kinds of monoclonal antibodies and SARS virus, which demonstrated the technique could be utilized as an immunoassay for qualitative and quantitative detection and kinetic analysis of biomolecule interaction.

\section{ACKNOWLEDGMENT}

The National Natural Science Foundation of China (No. 60178033, No. 90206029) and Chinese Academy of Sciences are gratefully acknowledged for their supports.

\section{REFERENCES}

[1] Poutanen SM, Low DE, Henry B, "Identification of severe acute respiratory syndrome in Canada," New Engl J, vol.348, pp.1995-2005, 2003.

[2] Peiris JS, Lai ST, Poon LL, Guan Y, Yam LY, Lim W,Nicholls J, et al, "Coronavirus as a possible cause of severe acute respiratory syndrome," Lancet, vol.361. pp.1319-1325, 2003a.

[3] Drosten C, Gunther S, Preiser W, van der Werf S, Brodt HR, Becker S, et al, "Identification of a novel coronavirus in patients with severe acute respiratory syndrome," New Engl J,vol.348, pp.1967-1976, 2003.

[4] Ksiazek TG, Erdman D, Goldsmith CS, Zaki SR, Peret T, Emery S, et al, "A novel Coronavirus associated with Severe Acute Respiratory Syndrome," New Engl J ,vol.348, pp. 1953-1966, 2003.

[5] G. Jin, P. Tengvall, I. Lundstršm and H. Arwin, "A Biosensor Concept Based on Imaging Ellipsometry for Visualization of Biomolecular Interactions," Analytical Biochemistry, vol.232, pp. 69-72, 1995.

[6] G. Jin, R. Jansson, and H. Arwin, "Imaging ellipsometry revisited: Developments for visualization of thin transparent layers on siliconsubstrates," Rev. Sci. Instrum, vol.67, pp. 2930-2936, 1996.
[7] Z-H. Wang, G. Jin, "A label-free multisensing immunosensor based on Imaging Ellipsometry,” Analytical Chemistry, vol.75, pp. 6119-6123, 2003.

[8] Z-Y. Zhao, G. Jin, Z. H. Wang, "Detection of somatotropin and corticosterone with imaging ellipsometry," in Proc. 20th Internation conference of the IEEE Engineering in Medicine and Bilogy Society, Hong Kong, pp. 269-272, 1998.

[9] Z-H. Wang, G. Jinaa, "Visualization of the interaction between IL-6 and IL-6R by imaging ellipsometry," Chinese Journal of Biotechnology, vol.18, pp. 99-101, 2002.

[10]H-G. Zhang, C. Qi, Z-H. Wang, G. Jin, and R-J Xiu, "Evaluation of a new CA15-3 protein assay method: optical protein-chip system for clinical application," Clinical Chemistry, In press.

[11]G. Jin, et al., unpublished.

[12]Z-H. Wang, G. Jin, unpublished.

[13]O. Hofmann, G. Voirin, P. Niedermann, and A. Manz, "Three-dimensional microfluidic confinement for efficient sample delivery to biosensor surfaces. Application to immunoassays on planar optical waveguides," Anal. Chem. vol.74, pp. 5243-5250, 2002.

[14]P-Q. Ying, G. Jin and Z. Tao, "Protein Competitive Adsorption Studied with Imaging Ellipsometry," In Proc. 2nd European Medical and Biological Engineering Conference, Vienna, Austria, pp. 190-191, 2002.

[15]P-Q. Ying, G. Jin, and Z. Tao, "Competitive adsorption of collagen and bovine serum albumin - Effect of the surface wettability," Colloids and surfaces B: biointerfaces, vol.33, pp. 259-263, 2004.

[16]G. Jin, Z-H. Wang, C. Qi, Z-Y. Zhao, S. Chen, Y-H. Meng, et al. "Immune-microarray with optical proteinchip for protein detection," Proceedings of the 25th annual international conference of the IEEE EMBS, Cancun Mexico, pp. 3575-3577, September 2003.

[17]G. Jin, Z. H. Wang, "Micro-systems for Optical Protein-Chip," International Journal of Nonlinear Sciences and Numerical Simulation, vol.3, pp. 191-194, 2002.

[18]G. Jin, Z. H. Wang, Y.H. Meng, P.Q. Ying, and L.H. Xia, "Optical ProteinChip as Microarrays for Protein Interaction Determination," In Proc. 23rd Annual International Conference of the IEEE Engineering in Medicine and Biology Society 25-28, Istanbul, Turkey. Oct 2001.

[19]Lin, Y.S., Hlady, V, "Human serum albumin adsorption onto octadecyldimethylsilyl-silica gradient surface". Colloids and Surfaces B: Biointerfaces, vol.2, pp. 481-491, 1994. 